42

The Open
Cardiovascular
lournal

REVIEW ARTICLE

\title{
Donor-recipient Matching in Heart Transplantation
}

\author{
Aleksandra Oprzędkiewicz ${ }^{1}$, Hubert Mado ${ }^{1, *}$, Wioletta Szczurek² ${ }^{2}$ Mariusz Gąsior ${ }^{3}$ and Bożena Szyguła-Jurkiewicz ${ }^{3}$ \\ ${ }^{1}$ Student Scientific Society, 3rd Department of Cardiology, School of Medical Sciences in Zabrze, Medical University of Silesia, Katowice, Poland \\ ${ }^{2}$ Silesian Center for Heart Diseases in Zabrze, Poland \\ ${ }^{3} 3$ rd Department of Cardiology, School of Medical Sciences in Zabrze, Medical University of Silesia, Katowice, Poland
}

\begin{abstract}
:
Heart transplantation remains the treatment of choice for end-stage Heart Failure (HF). Due to the shortage of organs for transplantation and the occurrence of perioperative complications, a key problem is donor matching, which should result in increased survival and improved quality of life for patients. The success of this procedure depends on various parameters such as gender, weight, ABO blood group and Human Leukocyte Antigen (HLA) system of both the recipient and the donor. Furthermore, non-HLA antigens may also be valuable in donor-recipient matching. The aim of this article is to summarize the recent knowledge on the impact of various factors on accurate donor-recipient matching to heart transplantation.
\end{abstract}

Keywords: Heart failure, Heart transplant, Donor-recipient matching, Non-HLA, Chronic graft vasculopathy, Ventricular assist device.

\begin{tabular}{|l|l|l|l|}
\hline Article History & Received: July 15, 2020 & Revised: October 04, 2020 & Accepted: October 07, 2020 \\
\hline
\end{tabular}

\section{INTRODUCTION}

Heart Transplantation (HT) is the treatment of choice for suitable patients with advanced Heart Failure (HF), whose condition deteriorates despite optimal conventional treatment $[1,2]$. The most common causes of severe HF that require HT are myocardial infarction $(44 \%)$, post-inflammatory cardiomyopathy (44\%), congenital heart failure (3\%) and endstage of acquired heart defects (2\%) [3]. Other diseases, including heart tumors, together account for $4 \%$ of transplants, while re-transplants account for $2 \%$ [3]. As a result of the worldwide increase in life expectancy and significant progress in pharmacological and interventional treatment of $\mathrm{HF}$, the percentage of patients reaching the advanced stage of the disease is constantly growing $[4,5]$. Hence, an increasing number of patients qualify for HT, while the number of potential heart donors has remained unchanged for years $[4,5]$. This contributes to an increased imbalance between the demand for organs that can be transplanted and the number of patients awaiting transplantation. Therefore, the precise identification of patients who are most likely to benefit from HT is necessary due to the mentioned lack of organs and to avoid complications perioperatively as well as long term.

The International Society for Heart Transplantation (ISHLT) guidelines consider an insufficient number of factors in the selection of the best donor [6]. They refer to the ratio

\footnotetext{
* Address correspondence to this author at Student Scientific Society, 3rd Department of Cardiology, School of Medical Sciences in Zabrze, Medical University of Silesia, Katowice, Poland;

Tel: +48694138970; +48695948463; E-mail: hubert.mado@med.sum.edu.pl
}

between donor and recipient Body Mass Index (BMI), although not to other parameters affecting the prognosis of heart transplantation, such as gender, age and proper matching of the human leukocyte antigen (HLA) and ABO systems. It is worth mentioning that certain factors such as non-HLA antigens are currently not used in matching, however, due to their impact on graft outcome, they may prove useful in the future.

Many complications after HT are related to insufficient donor and recipient matching. Complications related to HT can be divided into postoperative, early and late [7]. Postoperative complications occur during the first days after surgery, early complications occur up to 1 year after surgery and late complications occur $>1$ year after HT $[3,7]$.

Postoperative complications include hyperacute rejection, cardiac tamponade and primary graft dysfunction [7]. Hyperacute rejection is a rare complication that occurs shortly after transplantation when HLA and non-HLA antigens are attacked via binding of antibodies to the allograft [7]. Early complications include the development of right ventricular dysfunction, arrhythmia, acute rejection and infections [7]. The main early complication is acute rejection; the second most common are infections [3, 7]. The mechanism of acute rejection is most commonly cellular and less often associated with antibodies [7]. Infections occurring after HT may be opportunistic or reactivate latent infections and are related to administered immunosuppression [7, 8]. Cytomegalovirus (CMV) infection affects up to $80 \%$ of transplant recipients 
depending on the immunosuppression used and requires special consideration [7]. For example, CMV infection may indirectly affect the occurrence of cardiac allograft vasculopathy (CAV) [8]. Late complications include CAV, malignancy and renal dysfunction [7]. CAV is a form of chronic rejection induced by the development of atherosclerotic deposits and inflammatory cells within the coronary arteries [7]. This complication is the main cause of late morbidity and mortality after HT [7]. Both renal dysfunction and malignancy (mostly skin cancer) are complications associated with the chronic use of post-HT immunosuppression to prevent the rejection of graft [7]. Among the drugs used in post-HT immunosuppression, calcineurin inhibitors are particularly nephrotoxic [7].

The aim of this review is to summarize the recent knowledge on the impact of various factors on effective donorrecipient matching for $\mathrm{HT}$.

\section{GENDER}

It is well known that there are differences in the function and structure of the myocardium between genders. The male heart has a larger volume of the right and left ventricle (LV), a larger LV mass and a lower LV ejection fraction than the female heart. This explains why a female heart transplanted into a male body cannot fulfill its circulation requirements, which leads to LV overgrowth, contractility impairment and anterograde graft failure [9 - 11].

The role of gender in HT is one of the best surveyed. Already in 1998, it was known that the increase in the number of episodes of rejection and a decrease in creatinine clearance in the first year after HT were mainly due to gender mismatch [9]. The gender difference is particularly important when the donor is female and the recipient is male. In the opposite situation, the studies did not reveal significant differences in mortality [10].

It has also been shown that male recipients who received female heart transplants reveal an increased progression of coronary vasculopathy. It is suggested that hemodynamic stress related to the smaller size of the transplanted heart and genderrelated differences in the immune response after HT are the causes of this phenomenon; however, the exact pathophysiological basis of this problem has not been identified [11].

Ideally, these facts should exclude women as potential heart donors for men. However, in the real world, it seems reasonable to pay special attention to men, who are the recipients of the female heart, as well as to the condition of their grafts.

\section{WEIGHT}

Weight is a crucial parameter, which was one of the first to be considered during matching. In the early 1990s, the rules required that the donor/recipient body weight ratio should not be $<0.8$ [12]. BMI is included in the ISHLT guidelines, and, as before, it is said that the difference in BMI between donor and recipient should not be $>20 \%$ [6]. The guidelines also recommend, more liberally than before, that no heart should be transplanted from a donor with the bodyweight $<70 \%$ of the recipient unless the organ comes from a male donor with the bodyweight $>70 \mathrm{~kg}$ [6]. Nevertheless, many researchers indicate that weight is not an adequate parameter for donor/recipient matching due to the fact that the main goal when selecting an organ for HT is to provide sufficient perfusion in the recipient's vascular bed, which depends more on the graft function and its size than on the donor body weight [13]. Investigations of the effect of undersized organs on mortality have shown that even if the bodyweight ratio was $<0.8$, this was not associated with worse results after transplantation, when transplanting male to male, female to female and male to female donors [14]. The only group with worse results after transplantation were female donors for male recipients [14]. To explain this phenomenon, Reeds et al. in 2014 calculated the predicted heart mass (PHM) of both genders $[15,16]$. PMH is an innovative estimated LV mass measure based on weight, height, sex and age $[16,17]$. This study revealed that even if the weight and height of the donor and recipient are the same, for opposite genders, the difference between their PHM is about 19\% [15]. Together with other physiological differences between the hearts of men and women described above, it may seem that BMI should be the second parameter, after gender, to be taken into account in donor-recipient matching for HT. However, the most recent reports indicate that the optimal measure of matching donor size to recipient size is PMH $[16,17]$. It has been shown that $\mathrm{PMH}$ is a better indicator than weight, height, BMI and body surface area [17]. These findings clearly suggest that in each case, PMH should be assessed and, where possible, the transplantation decision should be considered on the basis of this indicator.

The impact of oversizing in HT was also studied. Patel et al. observed no difference in the 5-year mortality rate between patients with undersized, properly sized or oversized heart in the weight ratio: $<0.8,0.8$ to 1.2 and $>1.2$ [18]. However, Schumer et al. reported that oversizing of the donor improves survival in patients with Left Ventricular Assist Device (LVAD) who underwent HT [19]. As an explanation for this phenomenon, two reasons are considered [19]. The first is the need for anticoagulants when using LVAD support, which leads to increased bleeding during surgery [19]. The second is the higher incidence of pulmonary hypertension in the group of LVAD patients, which leads to higher cardiac output after HT [19].

In the context of donor-recipient size matching, Bergenfeldt et al. reports seem to be the most crucial. Based on data from 52,455 adult heart transplants, a donor weight $<70 \%$ of the recipient's weight increases mortality in non-obese recipients, but does not affect mortality in obese recipients [20]. Moreover, the same study showed that gender mismatch increases mortality, regardless of the weight match.

\section{ABO BLOOD GROUP}

Appropriate blood type matching is one of the most wellknown factors in the search for the right donor. The need to match the recipient and the donor in terms of ABO blood groups affects not only the prognosis after HT, but also the waiting time for the procedure itself since the most common $\mathrm{ABO}$ blood groups in the world are $\mathrm{O}$ and $\mathrm{A}$ and the rarest are $\mathrm{B}$ and $\mathrm{AB}$. 
The following considerations use the division of blood groups into $3 \mathrm{ABO}$ compatibility groups: $\mathrm{ABO}-\mathrm{identical}$, $\mathrm{ABO}$-compatible and $\mathrm{ABO}$-incompatible [21].

Previous studies demonstrated that the mismatch in $\mathrm{ABO}$ blood group negatively affects survival after HT [22]. At the same time, it was found that the compatibility of this parameter between donor and recipient reduces the risk of acute rejection [23]. Nevertheless, nowadays, due to a large shortage of donors, it was investigated whether a minor mismatch in the ABO group negatively impacts 1 -year results. Neves et al. demonstrated that slight differences (interpreted as ABOcompatible) in $\mathrm{ABO}$ did not affect the prognosis of patients after HT and may shorten the HT waiting time in patients with rarer blood groups [23]. The results of others also confirmed that an identical match does not have to be preferable to a compatible, non-identical match of ABO blood group, especially in critically ill patients who can no longer wait for an identical donor [24]. A comparable observation was made by Jawitz et al. However, this study showed that special attention should be paid when the donor's blood group is $\mathrm{O}$, as in this case, it is associated with decreased graft survival [21]. The pathophysiological background of this phenomenon is not exactly known. It was considered whether the cause is more related to the prevalence of each blood group in the population. Since hearts from blood group, O donors are mainly transplanted to blood group O or B recipients, and group B is less common in the population, patients wait longer for an HT, and this fact is associated with their worse condition until surgery. Moreover, it is said that blood group $\mathrm{O}$ is the "allembracing donor", which may be the reason why even O-group recipients may have to wait longer for their $\mathrm{ABO}$-identical donor. Additionally, Bergenfeldt et al. demonstrated that the survival of patients $<55$ years of age with $\mathrm{AB}$ blood group, in whom the heart was transplanted from an $\mathrm{O}$ donor group, improved compared with patients with $\mathrm{ABO}$-identical donor group [25].

Although blood groups were one of the first parameters used in HT to properly match the donor and recipient, current research seems to support the thesis that a slight mismatch in $\mathrm{ABO}$ groups reduces mortality as it shortens the waiting time for HT [26]. Furthermore, there are reports of acceptable results of ABO-incompatible renal grafts in adults, ABOincompatible HT in pediatric patients, as well as reports about no differences in the incidences of deaths and re-transplants between ABO-compatible and ABO-incompatible HT [27]. Such reports suggest that ABO-incompatible HT could also potentially be more widely used in adults. Nevertheless, nowadays, this kind of transplantation is performed exceptionally due to the lack of standardization of immunosuppression protocols, high risk of rejection and unclear long-term prognosis [27]. However, various innovative methods for ABO-incompatible HT are currently under investigation; for example, placing an anti-A/B immunoadsorption column in the cardiopulmonary bypass system to remove isohemagglutinins anti-A and anti-B [28]. The absence of detectable anti-A IgM titers has been shown to remain at least until the fifth day after operation, followed by a rebound to $1: 4$ on day 14 and a decrease to $1: 1$ on day 34 , which lasted until the last test performed on day 54 after operation [28]. Such methods have promising results, which allows us to believe that incompatible AB-O transplants may be further considered in the future [28].

\section{HUMAN LEUKOCYTE ANTIGEN (HLA)}

HLA matching in HT seems to be one of the most controversial issues. While the significance of this parameter for kidney transplantation is rather unquestionable [29], in the case of HT, it has not been clearly determined how an HLA mismatch affects the future of the transplanted patient.

Early studies by Frist et al. did not demonstrate the effect of HLA matching on early graft rejection; however, the authors have shown that infections were more common in patients with lower HLA compatibility [30]. Twenty years later, Almenar et al. disclaimed this thesis [31]. In their study, the degree of HLA matching was not found to significantly affect the survival of patients, development of infections or episodes of rejection [31]. Butts et al. noticed that the higher degree of donor-recipient HLA matching is associated with reduced graft loss in pediatric HT [32]. Nevertheless, this study showed no difference in the frequency of early rejection and the development of coronary artery vasculopathy [32]. Although earlier episodes of rejection have not been detected in pediatric transplantology, in adults after HT, Kilic et al. have observed them [33].

The most recent studies have reported the presence of HLA Donor Specific Antibodies (DSA), which have been recognized as the most important risk factors of rejection in HT [34, 35]. In this case, HLA is used to predict possible future rejection of the graft rather than as a parameter to be considered for the donor-recipient matching.

The effect of HLA matching in HT seems to be rather vague. However, it is possible that HLA may be used in this area in the future. Ansari et al. based on data from 25,583 heart transplants, showed a relationship between reduced long-term survival ( $>15$ years) after HT and a higher degree of HLA-A compatibility in patients with HLA-B and/or HLA-DR incompatible grafts [36]. Although the HLA-A mismatch was related to lower mortality due to chronic rejection, this study showed that the HLA-DR or HLA-B mismatch was not associated with improved survival [36]. In any case, despite many years of research, it is not yet clear how matching the right donor and recipient in terms of HLA has changed the prognosis after HT. Further research is needed. Regardless of the unclear role in matching, HLA, as mentioned earlier, is a useful parameter in assessing the prognosis after HT.

The association of information about DSA with the clinical outcome after HT revealed that patients who were found to have DSA are at greater risk of antibody-mediated rejection (AMR) and have worse transplant outcomes [37, 38]. It was also demonstrated that circulating complement-activating antiHLA DSA had particularly harmful effects on the survival of solid organ graft and the risk of rejection [39]. Therefore, they may be used in the future as a biomarker for individual noninvasive patient risk stratification [39].

\section{NON-HLA ANTIGENS - IMPORTANT PARAMETERS IN DONOR-RECIPIENT MATCHING IN THE FUTURE?}

An important aspect, however, which is currently not 
directly related to donor-recipient matching, is the presence of non-HLA antigens. Despite the progress in immunosuppression and optimal patient management, antibody-mediated rejection is still the main barrier to the long-term survival of the transplanted heart [40]. As many as $40 \%$ of the antibodymediated rejection (AMR) of heart transplants confirmed by biopsy showed no antibodies specific for HLA of the donor in peripheral blood of the recipient $[41,42]$. Nevertheless, AMR in heart transplants in the absence of anti-HLA DSA is still not well documented. Many non-HLA-specific antigens are expressed in the vascular endothelium and often occur due to stress or graft damage, but it is still not feasible to detect many of them [43]. However, antibodies directed against non-HLA antigens have been shown to be associated with dysfunction or rejection of the graft.

The best-known non-HLA antigens include major histocompatibility complex class I chain-related gene A (MICA), angiotensin II type 1 receptor (AT1R), endothelin-1 type A receptor (ETAR), vimentin and myosin [43, 44]. AntiMICA antibodies are linked to acute rejection and AMR [45 47]. On the other hand, the presence of anti-AT1R autoantibodies alone prior to transplantation is not associated with cell-mediated rejection (CMR) and AMR, but when antiAT1R and de novo formed donor-specific anti-HLA antibodies are present, the incidence of both CMR and AMR increases $[47,48]$. This suggests that damage to the transplanted heart by anti-HLA antibodies may cause increased exposure to neoantigens, which in turn leads to the formation of anti-HLA antigens. It is also worth noting that the presence of antibodies to non-HLA antigens may increase the risk of HLA-specific antibodies [49]. New discoveries suggest that non-HLA antibodies are associated with DSA-positive AMR, although, in this case, their role is not well known [42]. Increased levels of anti-AT1R and anti-ETAR antibodies are also associated with AMR and CMR processes [47, 50]. Non-HLA antigens further influence the occurrence of transplant-associated coronary artery disease, also called chronic graft vasculopathy (CGV). It has been reported that the presence of anti-vimentin antibodies is a predictor of CGV, whereas anti-myosin antibodies and myosin reactive $\mathrm{T}$-cells are involved in the pathogenesis of CGV [44, 47, 51, 52].

Commercial reagents for the determination of antibody levels against MICA, AT1R and ETAR have been available for a relatively short time, and due to the previously described reports, their value should be highlighted, especially in the case of AMR unrelated to DSA [49, 53]. These findings also prove that both HLA and non-HLA antibodies should be taken into account when assessing the patient's immune risk. Currently, donor-recipient matching for non-HLA antigen compatibility is not available, although it may be possible in the future, as this could significantly improve graft outcome. However, this topic is not currently well understood and further research is needed.

\section{CONCLUSION}

It appears that ABO-identical matching is not necessary for HT. Similarly, there is no clear evidence of the negative impact of the HLA mismatch, although DSA detection is useful in assessing the risk of rejection after HT. The most important parameter in donor-recipient matching seems to be gender, as the physiological differences between the cardiovascular systems of women and men are very difficult to overcome. Weight is also important in ABO-identical matching; however, recent studies indicate that $\mathrm{PMH}$ is a more appropriate parameter to use.

\section{CONSENT FOR PUBLICATION}

Not applicable.

\section{FUNDING}

None.

\section{CONFLICT OF INTEREST}

The authors declare no conflict of interest, financial or otherwise.

\section{ACKNOWLEDGEMENTS}

Declared none.

\section{REFERENCES}

[1] Bhagra SK, Pettit S, Parameshwar J. Cardiac transplantation: indications, eligibility and current outcomes. Heart 2019; 105(3): 252-60.

[http://dx.doi.org/10.1136/heartjnl-2018-313103] [PMID: 30209127]

[2] Mado H, Szczurek W, Gąsior M, Szyguła-Jurkiewicz B. Adiponectin in heart failure. Future Cardiol 2020 Sep 11;

[http://dx.doi.org/10.2217/fca-2020-0095] [PMID: 32915067]

[3] Zembala M, Zakliczyński M, Przybylski R, Wojarski J. Przeszczepienie serca. In: Hryniewiecki T, Pruszczyk P, Eds. Wielka interna - kardiologia z elementami angiologii - część 2 [Internet] 2018.[cited 2020 Aug 22]. Polish. Available from: https://podyplomie.pl/wiedza/wielka-interna/950,przeszczepienie-serca

[4] Friedrich EB, Böhm M. Management of end stage heart failure. Heart 2007; 93(5): 626-31.

[http://dx.doi.org/10.1136/hrt.2006.098814] [PMID: 17435073]

[5] Mozaffarian D, Benjamin EJ, Go AS, et al. Heart disease and stroke statistics-2016 update: A report from the american heart association. Circulation 2016; 133(4): e38-e360.

[http://dx.doi.org/10.1161/CIR.0000000000000350] [PMID: 26673558]

[6] Mehra MR, Canter CE, Hannan MM, et al. The 2016 International society for heart lung transplantation listing criteria for heart transplantation: A 10-year update. J Heart Lung Transplant 2016; 35(1): 1-23.

[http://dx.doi.org/10.1016/j.healun.2015.10.023] [PMID: 26776864]

[7] Shah KS, Kittleson MM, Kobashigawa JA. Updates on heart transplantation. Curr Heart Fail Rep 2019; 16(5): 150-6. [http://dx.doi.org/10.1007/s11897-019-00432-3] [PMID: 31240638]

[8] Potena L, Zuckermann A, Barberini F, Aliabadi-Zuckermann A. Complications of cardiac transplantation. Curr Cardiol Rep 2018; 20(9): 73 .

[http://dx.doi.org/10.1007/s11886-018-1018-3] [PMID: 29992503]

[9] Prendergast TW, Furukawa S, Beyer AJ III, Browne BJ, Eisen HJ, Jeevanandam V. The role of gender in heart transplantation. Ann Thorac Surg 1998; 65(1): 88-94.

[http://dx.doi.org/10.1016/S0003-4975(97)01105-3] [PMID: 9456101]

[10] Weiss ES, Allen JG, Patel ND, et al. The impact of donor-recipient sex matching on survival after orthotopic heart transplantation: analysis of 18000 transplants in the modern era. Circ Heart Fail 2009; 2(5): $401-8$.

[http://dx.doi.org/10.1161/CIRCHEARTFAILURE.108.844183] [PMID: 19808369]

[11] Erinc K, Yamani MH, Starling RC, et al. The influence of donor gender on allograft vasculopathy: evidence from intravascular ultrasound. Transplant Proc 2004; 36(10): 3129-31. [http://dx.doi.org/10.1016/j.transproceed.2004.10.072] 15686711]

[12] Reichart B. Size matching in heart transplantation. J Heart Lung 
Transplant 1992; 11(4 Pt 2): S199-202.

[PMID: 1515441]

[13] Eberlein M, Reed RM. Donor to recipient sizing in thoracic organ transplantation. World J Transplant 2016; 6(1): 155-64. [http://dx.doi.org/10.5500/wjt.v6.i1.155] [PMID: 27011913]

[14] Jayarajan SN, Taghavi S, Komaroff E, Mangi AA. Impact of low donor to recipient weight ratios on cardiac transplantation. J Thorac Cardiovasc Surg 2013; 146(6): 1538-43.

[http://dx.doi.org/10.1016/j.jtcvs.2013.06.028] [PMID: 23915920]

[15] Reed RM, Netzer G, Hunsicker L, et al. Cardiac size and sex-matching in heart transplantation : size matters in matters of sex and the heart. JACC Heart Fail 2014; 2(1): 73-83.

[http://dx.doi.org/10.1016/j.jchf.2013.09.005] [PMID: 24611131]

[16] Tremblay-Gravel M, Khush K. Predicted heart mass for donor organ allocation: Getting closer to the target. Circ Heart Fail 2019; 12(12)e006634

[http://dx.doi.org/10.1161/CIRCHEARTFAILURE.119.006634] [PMID: 31805782]

[17] Kransdorf EP, Kittleson MM, Benck LR, et al. Predicted heart mass is the optimal metric for size match in heart transplantation. J Heart Lung Transplant 2019; 38(2): 156-65.

[http://dx.doi.org/10.1016/j.healun.2018.09.017] [PMID: 30528987]

[18] Patel ND, Weiss ES, Nwakanma LU, et al. Impact of donor-torecipient weight ratio on survival after heart transplantation: Analysis of the United Network for Organ Sharing Database. Circulation 2008; 118(14)(Suppl.): S83-8.

[http://dx.doi.org/10.1161/CIRCULATIONAHA.107.756866] [PMID: 18824775]

[19] Schumer EM, Black MC, Rogers MP, et al. Donor oversizing results in improved survival in patients with left ventricular assist device. ASAIO J 2016; 62(5): 571-7.

[http://dx.doi.org/10.1097/MAT.0000000000000399] [PMID: 27258226]

[20] Bergenfeldt H, Stehlik J, Höglund P, Andersson B, Nilsson J. Donorrecipient size matching and mortality in heart transplantation: Influence of body mass index and gender. J Heart Lung Transplant 2017; 36(9): 940-7.

[http://dx.doi.org/10.1016/j.healun.2017.02.002] [PMID: 28259595]

[21] Jawitz OK, G Jawitz N, Yuh DD, Bonde P. Impact of ABO compatibility on outcomes after heart transplantation in a national cohort during the past decade. J Thorac Cardiovasc Surg 2013; 146(5): $1239-45$.

[http://dx.doi.org/10.1016/j.jtcvs.2013.06.040] [PMID: 23978472]

[22] Nakatani T, Aida H, Frazier OH, Macris MP. Effect of ABO blood type on survival of heart transplant patients treated with cyclosporine. J Heart Transplant 1989; 8(1): 27-33.

[PMID: 2647928]

[23] Neves C, Prieto D, Sola E, Antunes MJ. Heart transplantation from donors of different ABO blood type. Transplant Proc 2009; 41(3): 938-40.

[http://dx.doi.org/10.1016/j.transproceed.2009.01.061] [PMID: 19376393]

[24] Sjögren J, Ljungdahl-Waller F, Senneby E, Ekmehag B, Koul B, Nilsson J. Heart transplantation with ABO-identical versus ABOcompatible cardiac grafts: influence on long-term survival. Scand Cardiovasc J 2010; 44(6): 373-9.

[http://dx.doi.org/10.3109/14017431.2010.509450] [PMID: 21080866]

[25] Bergenfeldt H, Andersson B, Bućin D, et al. Outcomes after ABOincompatible heart transplantation in adults: A registry study. J Heart Lung Transplant 2015; 34(7): 892-8.

[http://dx.doi.org/10.1016/j.healun.2015.01.008] [PMID: 25754241]

[26] Hageman M, Michaud N, Chinnappan I, Klein T, Mettler B. ABOincompatible heart transplants. Perfusion 2015; 30(3): 209-12.

[http://dx.doi.org/10.1177/0267659114538895] [PMID: 24898580]

[27] Fuchs M, Schibilsky D, Zeh W, Berchtold-Herz M, Beyersdorf F, Siepe M. Does the heart transplant have a future? Eur J Cardiothorac Surg 2019; 55(Suppl. 1): i38-48.

[http://dx.doi.org/10.1093/ejcts/ezz107] [PMID: 31106338]

[28] Robertson A, Issitt R, Crook R, et al. A novel method for ABOincompatible heart transplantation. J Heart Lung Transplant 2018; 37(4): 451-7.

[http://dx.doi.org/10.1016/j.healun.2017.05.006] [PMID: 28554587]

[29] Williams RC, Opelz G, Weil EJ, McGarvey CJ, Chakkera HA. The risk of transplant failure with hla mismatch in first adult kidney allografts 2: Living donors, summary, guide. Transplant Direct 2017; $3(5) \mathrm{e} 152$

[http://dx.doi.org/10.1097/TXD.0000000000000664] [PMID:
28573187]

[30] Frist WH, Oyer PE, Baldwin JC, Stinson EB, Shumway NE. HLA compatibility and cardiac transplant recipient survival. Ann Thorac Surg 1987; 44(3): 242-6

[http://dx.doi.org/10.1016/S0003-4975(10)62062-0] [PMID: 3307658]

[31] Almenar L, Maeso ML, Martínez-Dolz L, et al. Influence of HLA matching on survival in heart transplantation. Transplant Proc 2005; 37(9): 4001-5.

[http://dx.doi.org/10.1016/j.transproceed.2005.09.145] [PMID: 16386610]

[32] Butts RJ, Scheurer MA, Atz AM, et al. Association of human leukocyte antigen donor-recipient matching and pediatric heart transplant graft survival. Circ Heart Fail 2014; 7(4): 605-11. [http://dx.doi.org/10.1161/CIRCHEARTFAILURE.113.001008] [PMID: 24833649]

[33] Kilic A, Weiss ES, Allen JG, et al. Simple score to assess the risk of rejection after orthotopic heart transplantation. Circulation 2012; 125(24): 3013-21.

[http://dx.doi.org/10.1161/CIRCULATIONAHA.111.066431] [PMID: 22634267]

[34] Sato T, Seguchi O, Kanaumi Y, et al. Clinical implication of noncomplement-binding donor-specific anti-hla antibodies in heart transplant recipients -risk stratification by c1q-binding capacity. Clin Surg 2017; 2: 1703.

[35] Barten MJ, Schulz U, Beiras-Fernandez A, et al. The clinical impact of donor-specific antibodies in heart transplantation. Transplant Rev (Orlando) 2018; 32(4): 207-17.

[http://dx.doi.org/10.1016/j.trre.2018.05.002] [PMID: 29804793]

[36] Ansari D, Bućin D, Höglund P, Ohlsson M, Andersson B, Nilsson J. Analysis of the influence of hla-a matching relative to hla-b and -dr matching on heart transplant outcomes. Transplant Direct 2015; 1(9)e38

[http://dx.doi.org/10.1097/TXD.0000000000000545] [PMID: 27500238]

[37] Clerkin KJ, Farr MA, Restaino SW, et al. Donor-specific anti-HLA antibodies with antibody-mediated rejection and long-term outcomes following heart transplantation. J Heart Lung Transplant 2017; 36(5): 540-5.

[http://dx.doi.org/10.1016/j.healun.2016.10.016] [PMID: 27916323]

[38] Kauke T, Oberhauser C, Lin V, et al. De novo donor-specific antiHLA antibodies after kidney transplantation are associated with impaired graft outcome independently of their C1q-binding ability. Transpl Int 2017; 30(4): 360-70.

[http://dx.doi.org/10.1111/tri.12887] [PMID: 27862352]

[39] Bouquegneau A, Loheac C, Aubert O, et al. Complement-activating donor-specific anti-HLA antibodies and solid organ transplant survival: A systematic review and meta-analysis. PLoS Med 2018; 15(5)e 1002572

[http://dx.doi.org/10.1371/journal.pmed.1002572] [PMID: 29799874]

[40] Singh N, Pirsch J, Samaniego M. Antibody-mediated rejection: treatment alternatives and outcomes. Transplant Rev (Orlando) 2009; 23(1): 34-46.

[http://dx.doi.org/10.1016/j.trre.2008.08.004] [PMID: 19027615]

[41] Zhang Q, Cecka JM, Gjertson DW, et al. HLA and MICA: targets of antibody-mediated rejection in heart transplantation. Transplantation 2011; 91(10): 1153-8.

[http://dx.doi.org/10.1097/TP.0b013e3182157d60] [PMID: 21544036]

[42] See SB, Mantell BS, Clerkin KJ, et al. Profiling non-HLA antibody responses in antibody-mediated rejection following heart transplantation. Am J Transplant 2020; 20(9): 2571-80.

[http://dx.doi.org/10.1111/ajt.15871] [PMID: 32190967]

[43] Zhang X, Reed EF. Effect of antibodies on endothelium. Am J Transplant 2009; 9(11): 2459-65.

[http://dx.doi.org/10.1111/j.1600-6143.2009.02819.x] [PMID: 19775314]

[44] Kalache S, Dinavahi R, Pinney S, Mehrotra A, Cunningham MW, Heeger PS. Anticardiac myosin immunity and chronic allograft vasculopathy in heart transplant recipients. J Immunol 2011; 187(2): 1023-30.

[http://dx.doi.org/10.4049/jimmunol.1004195] [PMID: 21677143]

[45] Suárez-Alvarez B, López-Vázquez A, Gonzalez MZ, et al. The relationship of anti-MICA antibodies and MICA expression with heart allograft rejection. Am J Transplant 2007; 7(7): 1842-8. [http://dx.doi.org/10.1111/j.1600-6143.2007.01838.x] [PMID: 17511763]

[46] Nath DS, Angaswamy N, Basha HI, et al. Donor-specific antibodies to human leukocyte antigens are associated with and precede antibodies 
to major histocompatibility complex class I-related chain A in antibody-mediated rejection and cardiac allograft vasculopathy after human cardiac transplantation. Hum Immunol 2010; 71(12): 1191-6. [http://dx.doi.org/10.1016/j.humimm.2010.09.012] [PMID: 20868717]

[47] Butler CL, Hickey MJ, Jiang N, et al. Discovery of non-HLA antibodies associated with cardiac allograft rejection and development and validation of a non-HLA antigen multiplex panel: From bench to bedside. Am J Transplant 2020; 20(10): 2768-80.

[http://dx.doi.org/10.1111/ajt.15863] [PMID: 32185871]

[48] Reinsmoen NL, Lai CH, Mirocha J, et al. Increased negative impact of donor HLA-specific together with non-HLA-specific antibodies on graft outcome. Transplantation 2014; 97(5): 595-601.

[http://dx.doi.org/10.1097/01.TP.0000436927.08026.a8] [PMID: 24162250]

[49] Zhang X, Reinsmoen NL. Impact of Non-Human Leukocyte AntigenSpecific Antibodies in Kidney and Heart Transplantation. Front Immunol 2017; 8: 434.

[http://dx.doi.org/10.3389/fimmu.2017.00434] [PMID: 28450866]
[50] Hiemann NE, Meyer R, Wellnhofer E, et al. Non-HLA antibodies targeting vascular receptors enhance alloimmune response and microvasculopathy after heart transplantation. Transplantation 2012; 94(9): 919-24.

[http://dx.doi.org/10.1097/TP.0b013e3182692ad2] [PMID: 23034559]

[51] Jurcevic S, Ainsworth ME, Pomerance A, et al. Antivimentin antibodies are an independent predictor of transplant-associated coronary artery disease after cardiac transplantation. Transplantation 2001; 71(7): 886-92

[http://dx.doi.org/10.1097/00007890-200104150-00011]

[PMID: 11349721

[52] Baldwin W III, Valujskikh A. Mechanisms underlying antibodymediated rejection. Circulation 2020; 141(6): 479-81.

[http://dx.doi.org/10.1161/CIRCULATIONAHA.119.044541] [PMID 32078432]

[53] Gates KV, Pereira NL, Griffiths LG. Cardiac non-human leukocyte antigen identification: Techniques and troubles. Front Immunol 2017; 8: 1332

[http://dx.doi.org/10.3389/fimmu.2017.01332] [PMID: 29093713]

\section{C) 2020 Oprzędkiewicz et al.}

This is an open access article distributed under the terms of the Creative Commons Attribution 4.0 International Public License (CC-BY 4.0), a copy of which is available at: https://creativecommons.org/licenses/by/4.0/legalcode. This license permits unrestricted use, distribution, and reproduction in any medium, provided the original author and source are credited. 